\title{
THE HEALTH CULTURE OF FUTURE DOCTORS THROUGH THE PRISM OF THE HEALTH-PRESERVING COMPETENCE FORMATION
}

DOI: 10.36740/WLek202108127

\author{
Nadiya 0. Fedchyshyn' ${ }^{1}$, Olha V. Romanchuk², Lesia I. Bilovus ${ }^{3}$, Oksana A. Mysyk', Viktor L. Nazaruk', \\ Nataliya M. Yablonska ${ }^{3}$, Tetiana I. Pantyuk ${ }^{4}$ \\ 'TERNOPIL NATIONAL MEDICAL UNIVERSITY, TERNOPIL, UKRAINE \\ 2IVAN BOBERSKY LVIV STATE UNIVERSITY OF PHYSICAL CULTURE, LVIV, UKRAINE \\ ${ }^{3}$ WEST UKRAINIAN NATIONAL UNIVERSITY, TERNOPIL, UKRAINE \\ ${ }^{4}$ IVAN FRANKO DROHOBYCH STATE PEDAGOGICAL UNIVERSITY, DROHOBYCH, UKRAINE
}

\begin{abstract}
The aim: To present the complex formation of all the outlined components and the interaction between them, it should be lead to the successful formation of a culture of health of future doctors.

Materials and methods: The diagnostic stage of the experimental study covered 450 students of four higher medical educational institutions: I. Horbachevsky TernopilState Medical University (150 students), Lviv National Medical University named after D. Halytsky (100 students); Bukovynian State Medical University (100 students), Ivano-Frankivsk National Medical University (100 students), Ukraine.

Results and conclusions: Analysis of the dynamics of changes in the formation of personal practical and personaldeveloping components of the future doctors' health culture from entry to final control allows us to conclude that the use of author's methods in preparing students gives better results than traditional training.
\end{abstract}

KEY WORDS: personal practical component, personaldeveloping component, health-preserving competence, future doctor, health culture

Wiad Lek. 2021;74(8):1931-1938

\section{INTRODUCTION}

The purpose of the PE teacher in the direction of forming a culture of future doctors health is to create a favorable environment in the educational process at the higher educational establishments. To achieve this goal, it is necessary to solve the following tasks: to create a stable motivation for students to form a health culture; create a healthy educational environment; to form the future doctors' culture of healthon the basis of general culture; to build the educational process in accordance with the purpose of humanistic education; to create a favorable motivational environment for learning and the desire for self-education and self-improvement $[1 ; 2]$.

In the context of our study, the personal values of the future doctor include the concepts of «health» and «health culture», due to the following statements: the practical significance of these concepts for the preservation and development of human life processes, which is why they have really important meaning; the formed culture of health as this special education is a certain reference point and ideal of the personality to which each student should aspire; health can be considered as a goal, the achievement of which allows a person to ensure a long and happy life, active social capacity in professional activities and in everyday life; health can be seen as a means to meet a person's basic needs by determining his or her life strategy [3-6].
The modern educational process at the higher school should not only be reduced to the formal transfer of knowledge from teacher to student, but should also perform such important functions as the formation of new motivational and value orientations of students, in particular in the field of health. The problem of human health is inseparable from the problem of human himself, it arises together with a human and changes according to the development of human culture. That is why modern medicine and the educated individuals come to understand the fact that the strategy of achieving human health through the treatment of diseases is not able to solve health problems in our country. In this regard, the ideas of health culture, the development of valeological thinking in the younger generation and student youth become relevant and in demand in the pedagogy of the 90 s in the twentieth century $[7 ; 8 ; 9]$.

To take into account various aspects of health care activities of future doctorsfully, the components (personal practical and personaldeveloping), criteria, indicators and levels of formation of students' health culture are specified. The criterion of the motivational-value component determines the motivation of students to master the culture of health as a personal value [10: 72].

The criterion of the personal practical component of the future doctor's health culture is the purposeful practical activity of students in the direction of skills formation. Ac- 
cording to the requirements of the curriculum for students of higher medical educational institutions of III-IV levels of accreditation [11], future doctors must be able: to apply knowledge of medical and biological disciplines in physical education classes; to carry out systematic physical training of health or sports orientation. The levels of formation of the practical component of the future doctors' health culture are determined by the following manifestations:

High level. Future doctors in a critical situation are able to provide qualified first aid; students have successfully mastered the ability to measure heart rate and blood pressure for themselves and others, as well as the ability to provide necessary and useful advice on maintaining and improving health; adhere to a balanced and rational diet and consumption of sufficient water, as well as diet and drinking regime; follow the rules of personal hygiene; they do not have such bad habits as drinking alcohol and smoking; conduct active propaganda work to help get rid of these habits to acquaintances and friends; take pharmaceuticals only for serious diseases on a doctor's prescription; take enough time to sleep and follow the habit of going to bed earlier;

Medium. Provision of qualified first aid, but not in full; prompt and accurate measurement of heart rate and blood pressure for yourself and other people; unsystematic observance of a balanced and rational diet and consumption of sufficient water; observance of rules of personal hygiene; overcoming such a bad habit as smoking and very minor and rare cases of alcohol consumption; correct, but not always justified intake of pharmaceuticals; allocating insufficient time for sleep; it is not always justified to spend time watching entertainment TV programs, movies, games on the computer and mobile phone;

Basic level. Insufficient full provision of qualified first aid and not always prompt and accurate measurement of heart rate and blood pressure; occasional observance of a balanced and rational diet and water consumption; insufficient observance of the rules of personal hygiene; trying to quit smoking and drinking only occasionally; often unjustified use of pharmaceuticals; allocating insufficient time for sleep; frequent unreasonable spending of time watching entertainment TV programs, movies, games on the computer and mobile phone; slight neglect of the culture of sexual relations;

Low level. Lack of skills in providing qualified medical care, as well as measuring heart rate and blood pressure for yourself and other people; practically non-compliance with the rules of balanced and rational nutrition, water consumption, drinking regime; violation of the rules of personal hygiene; Future doctors practically do not use health training of a professional-applied nature, do not master new methods and techniques of recovery, do not perform complexes of physical exercises that contribute to maintaining good health.

The criterion of the personal development component determines the orientation of students to self-improvement in the direction of health [12].

The levels of formation of the personal developing component are characterized by the following indicators:
High level. Future doctors are regularly engaged in physical culture and sports; constantly improve their physical fitness and form; systematically perform sets of exercises and hardening procedures and practice self-massage techniquesregularly; participate in various types of physical activity, while showing initiative in organizing and conducting physical culture and sports and health activities and attract new participants; ready to provide first aid, having previously taken all measures for their own safety and the safety of others; physical activity is sufficient both on school days and on weekends and holidays;

Medium. Students are regularly engaged in physical culture and sports, trying to improve physical fitness and fitness; complexes of exercises of morning hygienic gymnastics, hardening procedures and self-massage techniques are not always performed systematically; participate only in those types of physical activity that they are well versed in; measure heart rate and blood pressure in a state of illness or malaise; the amount of their motor activity is not always sufficient, especially in school days; agitation on the need for physical culture and sports is carried out periodically;

Basic level. Future doctors are not regularly engaged in physical culture and sports, do not improve physical fitness and formsufficiently; complexes of exercises of morning hygienic gymnastics, hardening procedures and self-massage techniques are rarely performed; participate in various types of physical activityinfrequently; heart rate and blood pressure are measured only in the state of the disease; the amount of motor activity is not sufficient, especially it is observed on school days; agitation on the need for physical culture and sports is poorly conducted; in conflict and stressful situations they often lose self-control; methods and methodsof prevention of the most widespread diseases in Ukraine are seldom applied in practice; poorly supported environmental clean-up initiatives.

Low level. Students are practically not engaged in physical culture and sports and thus reduce their physical fitness and form; neglect the performance of morning hygienic gymnastics, do not perform hardening procedures and self-massage techniques; their participation in various types of physical activity is limited to observation; the volume of their physical activity is low, and this applies to both physical culture and sports activities, leisure and everyday life; believe that physical culture and sports are everyone's own business and do not take any action in this direction; do not apply in practice the methods and techniques of prevention of the most common diseases in Ukraine.

To present the complex formation of all the outlined components and the interaction between them, it should be lead to the successful formation of a culture of health of future doctors $[13 ; 14]$. For the comprehensive implementation of all components of the future physicians' health culture, it is necessary to identify and implement certain pedagogical conditions that will contribute to the formative stage of the experimental study.

\section{THE AIM}

To present the complex formation of all the outlined components and the interaction between them, it should be lead to the successful formation of a culture of health of future doctors. 


\section{MATERIALS AND METHODS}

Experimental verification of the effectiveness of the formation of the future doctors' health culture of of by means of health technologies was conducted in the period from 2016 to 2020 academic years in three stages: diagnostic, ascertaining, formative.

The diagnostic stage of the experimental study covered 450 students of four higher medical educational institutions: I. Horbachevsky TernopilState Medical University (150 students), Lviv National Medical University named after D. Halytsky (100 students); Bukovynian State Medical University (100 students), Ivano-Frankivsk National Medical University (100 students).

\section{RESULTS AND DISCUSSION}

In the process of the diagnostic stage of the study, the formation of the future doctors' health culture in their second year of study at the Medical Universities (2018-2019 academic year) was established through observations, surveys, interviews and questionnaires. The obtained results made it possible to make the following generalizations: among 450 students 87 young people (19.33\%) had a high level of health culture; 105 students $(23.33 \%$ ) had a medium (sufficient) level of formation of this phenomenon; 180 students (40.0\%) had a basic (satisfactory) level, and 78 students (17.34\%) had a low (reproductive) level of health culture.

To determine the level of knowledge that is necessary for the formation of the future doctors' health culture, we conducted a survey of these students. Summarizing the results of the survey, which reflect the level of knowledge that is necessary for the formation of the future doctors' health culture, it can be stated that a high level is characteristic of 45 students, which is $17.71 \%$ of the total number of respondents, medium level was defined for 135 young people $(53,14 \%)$ and low level was distinguished for 74 students $(29.13 \%)$ respectively.

The results of another survey (to determine the level of skills of future doctors) allowed to distinguish the level of skills and abilities of students to set vital health indicators, which indicates a certain level of health culture among future doctors.

1. $29.52 \%$ of students use such important skills for the future doctor as measuring heart rate and blood pressure for themselves and other people. Half of the respondents (50\%) have doubts about the ability to do it quickly and as accurately as possible, and a fifth of students $(20.47 \%)$ do not know how to measure heart rate and blood pressure.

2. $68.11 \%$ of students will be able to provide qualified first aid in a critical situation, but $9.84 \%$ are not quite sure of their abilities, while $22.04 \%$ of future doctors will not be able to do so at all.

3. As for such an important component for the young organism as diet, it is systematically followed by $23.62 \%$ of students, $10.23 \%$ try to do it, but not always systematically and the majority of respondentspractically do not follow it, which is $66.14 \%$ of students.
4. Regarding the drinking regime (consumption of pure still water), it is constantly followed by $24.40 \%$ of students; $64.56 \%$ sometimes follow, and $11.02 \%$ of respondentspractically do not follow the drinking regime.

5. The students stated in their answers that they eat systematically, balanced and rationally (23.62\%); $9.05 \%$ sometimes eat a balanced and rational diet, and $67.32 \%$ of surveyed students do it sporadically.

6. Regarding the amount of consumption of clean drinking water, up to 1 liter per day is consumed by the majority of respondents $(55.11 \%)$, from 1 to 2 litersare used by $22.83 \%$ and more than 2 litersare drunk by $22.04 \%$ of students.

7. The vast majority of students (77.95\%) follow such important and simple rules of personal hygiene as systematic hand washing with soap before and after each meal; $17.71 \%$ of respondents do it sometimes and $4.33 \%$ of students follow these rules sporadically.

8 . The vast majority of respondents systematically brush their teeth twice a day $(80.31 \%)$; a much smaller part (16.14\%) sometimes do it systematically and a very small part of students (3.54\%) do it very rarely.

9. Carefully and responsibly select personal care and hygiene products in accordance with their skin type and body needs only $9.05 \%$ of students. The majority of respondents (62.59\%) rely on the opinion of acquaintances and friends, and $28.34 \%$ do not select at all, but use personal care and hygiene at random.

10. $41.12 \%$ of students abuse such a common and harmful habit as smoking; more than a third of respondents (35.82\%) had previously smoked, but were able to quit. The percentage of those students who have never smoked and are actively campaigning to help get rid of this negative habit of acquaintances and friends is $22.04 \%$ of respondents.

11. Alcoholic beverages are consumed by the vast majority of surveyed students, which is $58.26 \%$. The share of respondents who rarely drink alcohol is $23.62 \%$, and those who do not drink at all and try to persuade relatives, friends and acquaintances to get rid of excessive alcohol consumption $-18.11 \%$ of future doctors.

12. The survey showed that to some extent students are irresponsible about taking pharmaceuticals. In particular, $57.48 \%$ of students take medicines for mild headaches, abdominal pain and the first symptoms of a cold; with moderate headaches, abdominal pain and obvious cold symptoms, $28.74 \%$ of students take pharmaceuticals. Only $13.77 \%$ of future doctors take medicines only in extreme cases and with a doctor's prescription, and mild forms of disease try to treat folk remedies.

13. Students do not devote enough time to such an important restorative means for the young organism and its efficiency as sleep. In particular, $40.55 \%$ of future doctors sleep less than 7 hours a day; from 7 to 8 hours $46.85 \%$ and only $12.59 \%$ of students spend more than 8 hours a day sleeping.

14. Another important sign of the formation of the future doctors' health culture, in our opinion, is the habit of 
Table I. Data of the entry control results

\begin{tabular}{|c|c|c|c|c|c|c|c|c|c|c|}
\hline \multirow{3}{*}{$\begin{array}{l}\text { Elements of } \\
\mathrm{HC}\end{array}$} & \multirow{3}{*}{$\begin{array}{l}\text { Groups and } \\
\text { number od } \\
\text { students }\end{array}$} & \multicolumn{8}{|c|}{ Figures of the levels of future doctors' health culture } & \multirow{3}{*}{ Average } \\
\hline & & \multicolumn{2}{|c|}{ High } & \multicolumn{2}{|c|}{ Medium } & \multicolumn{2}{|c|}{ Basic } & \multicolumn{2}{|c|}{ Low } & \\
\hline & & NS & $\%$ & NS & $\%$ & NS & $\%$ & NS & $\%$ & \\
\hline \multirow{2}{*}{$\begin{array}{l}\text { Personal } \\
\text { practical }\end{array}$} & CG -180 & 36 & 20,0 & 42 & 23,33 & 72 & 40,0 & 30 & 16,67 & 3,47 \\
\hline & $\mathrm{EG}-181$ & 35 & 19,34 & 42 & 23,20 & 75 & 41,44 & 29 & 16,02 & 3,46 \\
\hline \multirow{2}{*}{$\begin{array}{c}\text { Personal } \\
\text { developing }\end{array}$} & CG -180 & 32 & 17,78 & 39 & 21,66 & 75 & 41,67 & 34 & 18,89 & 3,38 \\
\hline & $E G-181$ & 31 & 17,13 & 37 & 20,44 & 80 & 44,20 & 33 & 18,23 & 3,37 \\
\hline \multirow{2}{*}{ Total } & CG -180 & 35 & 19,44 & 42 & 23,33 & 72 & 40,0 & 31 & 17,22 & 3,45 \\
\hline & $E G-181$ & 34 & 18,78 & 40 & 22,10 & 77 & 42,54 & 30 & 16,58 & 3,43 \\
\hline
\end{tabular}

Hereandafter, we use the following abbreviations

$\mathrm{CG}$ - control group

EG - experimental group

$\mathrm{EC}$ - entry control

$\mathrm{FC}-$ final control

SC - stage control

$\mathrm{Al}$ - average indicator

NS - number of students

Table II. Data of the formation levels of the practical component of the future doctors' health culture

\begin{tabular}{|c|c|c|c|c|c|c|c|c|c|c|}
\hline \multirow{3}{*}{$\begin{array}{c}\text { Groups and } \\
\text { number of } \\
\text { students }\end{array}$} & \multirow{3}{*}{$\begin{array}{c}\text { Stages } \\
\text { of } \\
\text { control }\end{array}$} & \multicolumn{8}{|c|}{$\begin{array}{l}\text { Figures of the formation levels of the practical component of the future doctors' health } \\
\text { culture }\end{array}$} & \multirow{3}{*}{ Average } \\
\hline & & \multicolumn{2}{|c|}{ High } & \multicolumn{2}{|c|}{ Medium } & \multicolumn{2}{|c|}{ Basic } & \multicolumn{2}{|c|}{ Low } & \\
\hline & & NS & $\%$ & NS & $\%$ & NS & $\%$ & NS & $\%$ & \\
\hline \multirow{2}{*}{$\begin{array}{c}\text { CG } \\
180 \mathrm{st}\end{array}$} & EK & 36 & 20,0 & 42 & 23,33 & 72 & 40,0 & 30 & 16,67 & 3,47 \\
\hline & FK & 41 & 22,78 & 47 & 26,11 & 70 & 38,89 & 22 & 12,22 & 3,59 \\
\hline \multirow{2}{*}{$\begin{array}{c}\text { EG } \\
181 \mathrm{st} .\end{array}$} & EK & 35 & 19,34 & 42 & 23,20 & 75 & 41,44 & 29 & 16,02 & 3,46 \\
\hline & FK & 50 & 27,62 & 49 & 27,07 & 63 & 34,81 & 19 & 10,50 & 3,72 \\
\hline
\end{tabular}

going to bed earlier, because it indicates the so-called «healthy sleep». Thus, the majority of students who took part in the survey said that they go to bed after midnight (59.84\%); the share of those students who go to bed before midnight is $31.10 \%$ and only $9.05 \%$ go to bed before 23.00. This feature can be explained by extremely intense educational activities conducted by future doctors mainly at night, as well as poor living conditions, because very often students live in rooms of 3-4 or more people and interfere with each other in developing the correct mode of the day.

15. Despite the high workload of students in the educational process, $33.85 \%$ of them spend more than 2 hours a day on weekdays watching entertainment TV programs ore than 2 hours a day watching educational TV programs, movies, games on the computer and mobile phone; for $53 \%$ of students this time is slightly less and is from 1.5 to 2 hours; the remaining $12.99 \%$ of respondents spend no more than 1.5 hours a day.

16. On weekends and holidays, $63.38 \%$ of students spend more than 3 hours watching entertainment TV programs, movies and games on a computer and mobile phone; $27.16 \%$ of students from 2 to 3 hours and only $9.44 \%$ of respondents spend no more than 2 hours a day on these classes.
17. The vast majority of students who took part in the survey $(68.50 \%)$ talk on a mobile phone for more than 1 hour a day; $26.37 \%$ - from 30 minutes to 1 hour and only $5.1 \%$ of future doctors talk less than 30 minutes. This indicates that the vast majority of students, firstly, are significantly exposed to the harmful effects of radio waves, and, secondly, spend their free time in unnecessary conversations.

18. An important skill for the medical profession, such as helping people to provide necessary and useful advice on maintaining and improving health, is inherent in $18.89 \%$ of students. This skill is formed, but insufficiently, in $47.24 \%$ of respondents, and $18.89 \%$ of them did not show this skill at all. This indicates that future doctors need to be trained to make the most effective use of acquired knowledge and successfully communicate it to others.

19. A relevant topic, especially for today's youth, is the culture of sexual behavior, which involves the use of means of protection against unwanted pregnancies and sexually transmitted diseases. The results of the survey show that only $44.09 \%$ of students always use protection against pregnancy and sexually transmitted diseases; $47.63 \%$ do not always do it and $8.26 \%$ of respondents use them very rarely. 

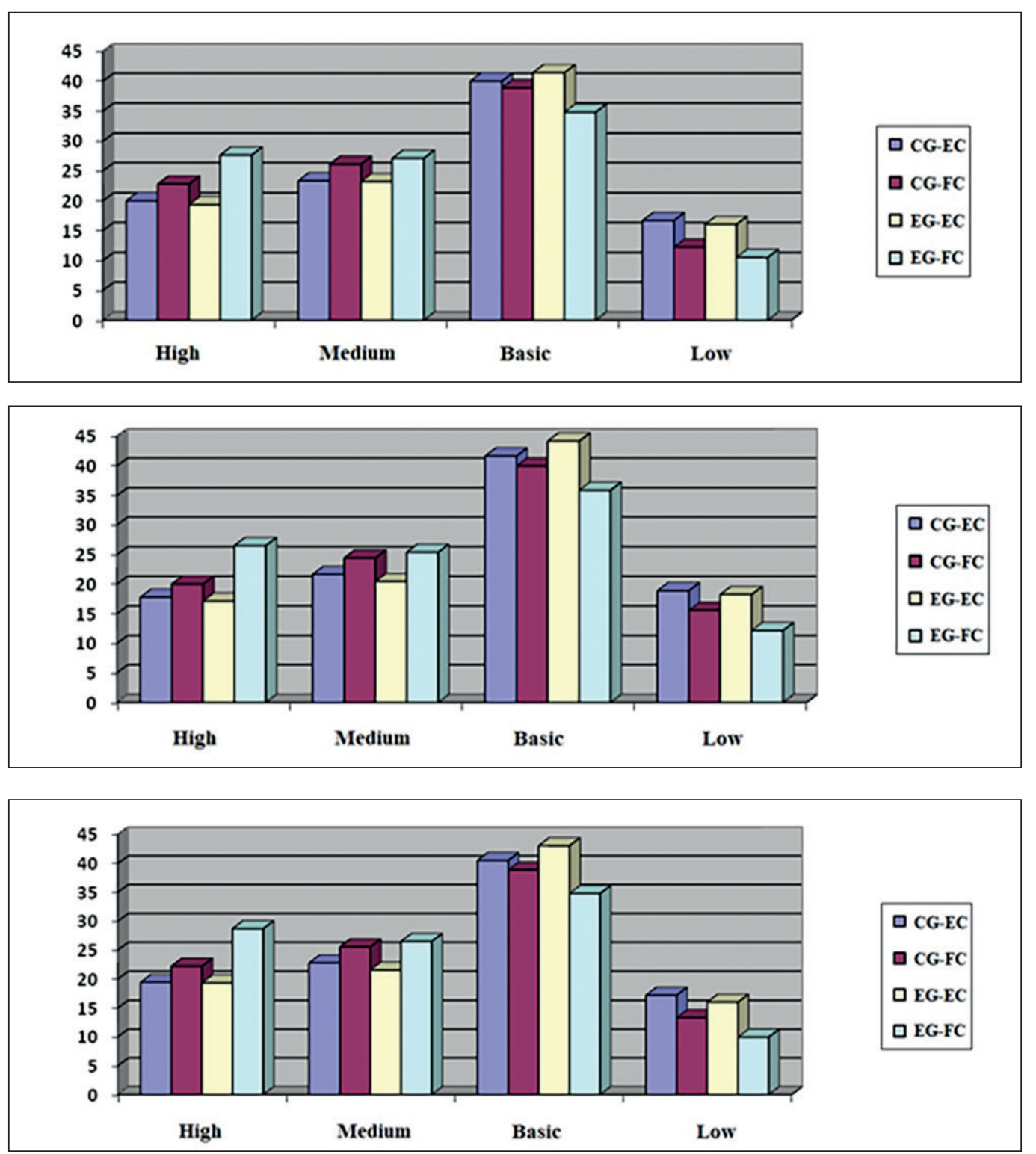

Fig. 1. Dynamics of indicators of levels of formation of practical-activity component of health culture of future doctors

Fig. 2. Dynamics of indicators of levels of formation of personal-developmental component of the future doctors' health culture

Fig. 3. Dynamics of the generalized indicators of formation levels of the future doctors' health culture
20. Only $9.44 \%$ of students have such an effective means of relieving stress and tension as self-massage; the share of those who have, but insufficiently, is $22.83 \%$ and those who do not have these techniques at all, $67.71 \%$ of future doctors.

Summing up the survey, which reflects the level of skill formation and abilities of future doctors, which indicate the formation of the practical aspect of health culture, it can be stated that a high level was reached by 65 students (25.59\%); medium - 83 students (32.67\%) and low - 103 students (40.55\%) respondents. It turns out that the skills and abilities of future doctors are formed much worse than the level of motivation and at about the same level with knowledge as important indicators of the formation of the health culture. In our opinion, this indicates that the problems that are closely related to the culture of health should be made as close as possible to practical life.

At the ascertaining stage of the experimental research, the first-year students (361 students) who started their studies at the Medical University were divided into control
(CG) and experimental groups (EG). In the control groups (13 groups in total) 180 students studied according to traditional methods. In the experimental groups (also 13 groups) of 181 students, the formation of the health culture was carried out by experimental methods. When dividing students into CG and EG, it is taken into account that the number of students in both categories of groups and the initial level of formation of all components of future doctors' health culture (HC) at the stage of entry control (EC) should be close to the value shown in table I.

Control and experimental groups were formed in such a way that they had as equal as possible among the total number of students. The initial level of culture among future doctors was also almost identical. The analysis of indicators of results of input control testifies to identical conditions of entrance of students of CG and EG in experimental research $[15 ; 16]$.

The analysis of indicators of formation of the personal practical component of the future doctors' health culture at the stage of entrance control in CG and EG groups shows 
Table III. The dynamics of the formation of the personal developing component of the future doctors' health culture

\begin{tabular}{|c|c|c|c|c|c|c|c|c|c|c|}
\hline \multirow{3}{*}{$\begin{array}{l}\text { Groups and } \\
\text { number of } \\
\text { stdents }\end{array}$} & \multirow{3}{*}{$\begin{array}{l}\text { Stage of } \\
\text { control }\end{array}$} & \multicolumn{8}{|c|}{$\begin{array}{l}\text { Figures of the formation levels of the personal developing component of the } \\
\text { future doctors' health culture }\end{array}$} & \multirow{3}{*}{ Average } \\
\hline & & \multicolumn{2}{|c|}{ High } & \multicolumn{2}{|c|}{ Medium } & \multicolumn{2}{|c|}{ Basic } & \multicolumn{2}{|c|}{ Low } & \\
\hline & & NS & $\%$ & NS & $\%$ & NS & $\%$ & NS & $\%$ & \\
\hline \multirow{2}{*}{$\begin{array}{c}\text { CG } \\
180 \mathrm{st}\end{array}$} & EK & 32 & 17,78 & 39 & 21,66 & 75 & 41,67 & 34 & 18,89 & 3,38 \\
\hline & FK & 36 & 20,0 & 44 & 24,44 & 72 & 40,0 & 28 & 15,56 & 3,49 \\
\hline \multirow{2}{*}{$\begin{array}{c}\mathrm{EG} \\
181 \mathrm{st} .\end{array}$} & EK & 31 & 17,13 & 37 & 20,44 & 80 & 44,20 & 33 & 18,23 & 3,37 \\
\hline & FK & 48 & 26,52 & 46 & 25,41 & 65 & 35,91 & 22 & 12,16 & 3,66 \\
\hline
\end{tabular}

Table IV. Generalized results of the formation of the future doctors' health culture

\begin{tabular}{|c|c|c|c|c|c|c|c|c|c|c|}
\hline \multirow{3}{*}{$\begin{array}{l}\text { Groups and } \\
\text { number of } \\
\text { stdents }\end{array}$} & \multirow{3}{*}{$\begin{array}{l}\text { Stage of } \\
\text { control }\end{array}$} & \multicolumn{8}{|c|}{ Generalized results of the formation of the future doctors' health culture } & \multirow{3}{*}{ Average } \\
\hline & & \multicolumn{2}{|c|}{ High } & \multicolumn{2}{|c|}{ Medium } & \multicolumn{2}{|c|}{ Basic } & \multicolumn{2}{|c|}{ Low } & \\
\hline & & NS & $\%$ & NS & $\%$ & NS & $\%$ & NS & $\%$ & \\
\hline \multirow{2}{*}{$\begin{array}{c}\text { CG } \\
180 \text { ст. }\end{array}$} & EK & 35 & 19,44 & 42 & 23,33 & 72 & 40,0 & 31 & 17,22 & 3,45 \\
\hline & FK & 39 & 21,67 & 47 & 26,11 & 69 & 38,33 & 25 & 13,89 & 3,56 \\
\hline \multirow{2}{*}{$\begin{array}{c}\text { EG } \\
181 \text { ст. }\end{array}$} & EK & 34 & 18,78 & 40 & 22,10 & 77 & 42,54 & 30 & 16,58 & 3,43 \\
\hline & FK & 51 & 28,18 & 49 & 27,07 & 62 & 34,25 & 19 & 10,50 & 3,73 \\
\hline
\end{tabular}

that the average score was 3.47 points in CG and 3.46 points in EG. The percentages of formation of this component at each level were very close. With a high level in CG was $20 \%$, in EG - 19.34\%; the medium level was found in CG $23.33 \%$, and in EG - $23.20 \%$ of future doctors; the basic level was inherent in CG $40.0 \%$, and in EG - 41.44\% of students; with a low level in CG was $16.67 \%$, and in EG $16.02 \%$ of students.

The analysis of the formation of the personaldeveloping component of the future doctors' health culture at the stage of entrance control in CG and EG groups shows that before the formative stage of the experimental study EG students had slightly lower average score - in CG - 3.38 points, and in EG - 3.37 points, which is 0.01 points less than students in the control groups; with a high level of formation of the personaldeveloping component of health culture in CG was $17.78 \%$, in EG - 17.13\% of students; with an average level in CG was $21.66 \%$, and in EG - 20.44\% of students; with the basic level $-41.67 \%$ in CG and $44.20 \%$ of students in EG; $18.89 \%$ of CG students and $18.23 \%$ of experimental students found a low level.

The analysis of the generalized indicators of the formation of the future doctors' health culture at the stage of entrance control shows that a high level is characterized by $19.44 \%$ of CG students and $18.78 \%$ of EG students; at the average level in CG was $23.33 \%$ of students, and in EG - 22.10\%; for the basic level - in CG - $40.0 \%$, and in EG - 42.54\%; at low level - in CG - 17.22\%, and in EG $16.58 \%$ of students; it was found that the average score in CG - 3.45 points, and in EG -3.43 points, which is 0.02 points less than in students of control groups.

Thus, the analysis of the results of the observational stage of the experiment shows that the numerical indicators of the formation of all components and the general health culture of future doctors, students of control groups entered the experimental study even with slightly better results than EG students. Figures concerning the levels of the practical component formation are shown in table II.

Analysis of the table II shows that

- according to high level figures, there is an increase in the number of students in CG from $20.0 \%$ to $22.78 \%$ (by $2.78 \%$ ), and in $\mathrm{EG}$ - from $19.34 \%$ to $27.62 \%$ (by $8.38 \%$ ), which is $6.1 \%$ more than CG students;

- according to the figures of the medium level there were changes in the direction of growth of CG students from $23.33 \%$ to $26.11 \%$ (by $2.78 \%$ ), and in EG - from $23.20 \%$ to $27.07 \%$ (by $3.87 \%$ ) ), which is $1 \%$ more than CG students; - according to the data of the basic level in the control groups there was a decrease in the number of students from $40.0 \%$ to $38.89 \%$ (by $1.11 \%$ ), and in EG - from $41.44 \%$ to $34.81 \%$ (by $6.63 \%$ ) ), which is $5.52 \%$ more than CG students;

- according to the figures of low level in the control groups there was a decrease in students from $16.67 \%$ to $12.22 \%$ (by $4.45 \%$ ), and in EG - from $16.02 \%$ to $10.5 \%$ (by $5.52 \%$ ), which is $1.07 \%$ more than the students of CG and indicates the need to improve the practical and activity aspect of the formation of a culture of health of future doctors; - the average evaluation of students in the control groups showed an increase in this indicator from 3.47 to 3.59 points (by 0.12 points), and in EG - from 3.46 to 3.72 points (by 0.26 points), which is 0.14 points more than CG students.

The diagrams (Fig. 1) show the dynamics of changes in the quantative indicators of the formation levels of the practical component of the future doctors' health culture.

Figures of the formation levels of the personaldeveloping component are shown in table III:

- according to high level indicators, there was an increase in the number of students in CG from $17.78 \%$ to $20.0 \%$ (by 
$2.22 \%$ ), and in EG - from $17.13 \%$ to $26.52 \%$ (by $9.39 \%$ ), which is $7.17 \%$ more than CG students;

- according to the indicators of the medium level, the number of CG students has increased from $21.66 \%$ to $24.44 \%$ (by $2.78 \%$ ), and in EG - from $20.44 \%$ to $25.41 \%$ (by $4.97 \%$ ), which is $2.19 \%$ more than students CG;

- according to the data of the basic level in the control groups there was a decrease in the number of students from $41.67 \%$ to $40.0 \%$ (by $1.67 \%$ ), and in EG - from $44.20 \%$ to $35.91 \%$ (by $8.29 \%$ ) ), which is $6.62 \%$ more than CG students;

- according to the indicators of low level in the control groups there was a decrease in students from $18.89 \%$ to $15.56 \%$ (by $3.33 \%$ ), and in EG - from $18.23 \%$ to $12.16 \%$ (by $6.07 \%$ ), which is $2.74 \%$ more than CG students;

- the average evaluation of students in the control groups was observed as an increase from 3.38 to 3.49 points (by 0.11 points), and in EG - from 3.37 to 3.66 points (by 0.29 points), which is 0.18 points more than CG students. According to the diagrams in Fig. 2. the dynamics of changes in the indicators of the formation levels of personal developing component of the future doctors' health culture can be traced.

The generalized results of indicators of levels of formation of culture of health of future doctors are given in tab. IV.

Analysis of the table IV indicates that

- according to high level indicators, there is an increase in the number of students in the control groups from $19.44 \%$ to $21.67 \%$ (by $2.23 \%$ ), and in the experimental groups - from $18.78 \%$ to $28.18 \%$ (by $9.4 \%$ ), which is $7.17 \%$ more than CG students;

- according to the indicators of the average level there was an increase in the number of students in CG from $23.33 \%$ to $26.11 \%$ (by $2.78 \%$ ), and in EG - from $22.10 \%$ to $27.07 \%$ (by $4.94 \%$ ), which is $2.19 \%$ more than CG students;

- according to the indicators of the basic level in the control groups there was a decrease in the number of students from $40.0 \%$ to $38.33 \%$ (by $1.67 \%$ ), and in EG - from $42.54 \%$ to $34.25 \%$ (by $8.29 \%$ ) ), which is $6.62 \%$ more than CG students;

- according to low level indicators in the control groups there was a decrease in the number of students from $17.22 \%$ to $13.89 \%$ (by $3.33 \%$ ), and in EG - from $16.58 \%$ to $10.50 \%$ (by $6.08 \%$ ) ), which is $2.75 \%$ more than students in the control groups;

- the average indicator of students in the control groups showed an increase in this indicator from 3.45 to 3.56 points ( 0.11 points), and in EG - from 3.43 to 3.73 points ( 0.3 points), which is 0.19 points more than students in the control groups.

The diagrams (Fig. 3) show the dynamics of changes in the indicators of the level of health culture of future doctors.

A comparative analysis of tabular data and charts shows that in both categories of groups there are students with a low level of future doctors' health culture. Therefore, the improvement of students' professional training at the higher educational establishments in the direction of forming a health culture should be carried out not only in the first or second year, when physical education classes are held, but also in the senior years.

The results of diagnosing the state of future doctors' health culture at the ascertaining stage of the experimental study showed that the percentage of students who achieved a high level of health culture was $25.59 \%$. There were slightly more students with a low level of health culture, namely $33.46 \%$. The share of students who belonged to the middle level was $40.95 \%$. Given the outlined shortcomings that hinder the successful formation of a health culture of medical students, on the basis of the developed special literature, own practical pedagogical experience and the results of the questionnaire developed practical recommendations for their elimination.

\section{CONCLUSION}

Analysis of the results of the formation of the personaldeveloping component of thefuture doctors' health culture at the stage of entrance control in CG and EG groups shows that before the formative stage of the experimental study EG students had slightly lower average score: in CG - 3.38 points, and in EG - 3.37 points, which is 0.01 points less than students in the control groups; with a high level of formation of the personaldeveloping component of health culture in CG was $17.78 \%$, in EG - 17.13\% of students; with a medium level in CG was $21.66 \%$, and in EG - 20.44\% of students; with the basic level $-41.67 \%$ in CG and $44.20 \%$ of students in EG; $18.89 \%$ of CG students and $18.23 \%$ of experimental students found a low level.

Thus, the analysis of the results of the observational stage of the experiment showed that the students of the control groups entered the experimental study even with slightly better indicators than the students of the experimental groups.

Analysis of the dynamics of changes in the formation of personal practical and personaldeveloping components of the future doctors' health culture from entry to final control allows us to conclude that the use of author's methods in preparing students gives better results than traditional training.

\section{REFERENCES}

1. Great dictionary of modern Ukrainian language. 2005: 1728.

2. Honcharenko S. Ukrainian pedagogical dictionary. 1997: 376.

3. Melnychuk, I., Fedchyshyn, N., Pylypyshyn, 0., Vykhrushch, A. Philosophical and Cultural Aspects of Medical Profession: Philosophical and Conceptual Peculiarities. Cultura. International Journal of Philosophy of Culture and Axiology. 2019; 16 (1): 165-174.

4. Vykhrushch, A., Drach I., Stefanyshyn K. et al. The System of Basic Concepts in Modern Science. International Journal of Applied Exercise Physiology. 2020; 9 (7):73-79. doi: 10.26655/JAAEP.2020.7.1;

5. Zavydivs'ka N. Peculiarities of formation of general physical culture and health education of students in the conditions of health-preserving education. 2014: 37-42.

6. Burgess-Pinto E., Yastremska S., Fedoniuk L. et al. Sustainable Development Principles in Health Promotion and Nursing Edecation. Medical Edication. 2019; 4(85): 67-73. doi: 10.11603/me.24145998.2019.4.10863 
7. Grushko V. Human health and the basics of a healthy lifestyle: textbook for the course «Valeology». 2012: 386.

8. Zhdanova E. The formation of a value attitude to health among students of a pedagogical university. 2005: 206.

9. Fedchyshyn N., Klishch H., Horpinich T., Yelahina N. Echoes of the Herbartianism in Western Ukraine (late 19 th - early 20 th centuries). Cultura. International Journal of Philosophy of Culture and Axiology. 2018; 15 (1): 103-114. doi: 10.3726/CUL.2018.01.06.

10. FedchyshynN., VykhrushchA., Bilavych H.etal. Development of Medical Students' Foreign Language Lexical Competence in the Virtual Learning Environment. Annals of the University of Craiova. Linguistics and Philology. 2020; 1-2: 71-79.

11. Typical program of the normative educational discipline «Physical Education» (for students of higher medical educational institutions of I-IV levels of accreditation). 2013: 15.

12. Prontenko K.V., Griban G.P., Bloshchynskyil.G. etal. Improvement of students' morpho-functional development and health in the process of sport-oriented physical education. Wiad Lek. 2020; 73(1): 161-168.

13. Vykhrushch A., Fedhyshyn N., Khvalyboha T. etal. Development of Students-Foreigners' Communicative Competence by Means of Information Technologies under the Conditions of the Medical University. International Journal of Higher Education. 2020; 9(6). 276285. doi: 10.5430/ijhe.v9n6p276

14. Kachenovskij M. Introduction to valueology pedagogy. 1996: 68.

15. Nazaruk V. Organization of experimental study on forming a health culture of future doctors by means of health-supporting technologies. Journal of Education, Health and Sport. 2015; 5(1): 241-248.

16. Law of Ukraine"About higher education". 2015; 76-VIII (28.12.2014): 6.
The work was carried out according to the research work of Ternopil National Medical University for 2019-2021 on the theme of "Professional training of future specialists in the medical field on the basis of interdisciplinary integration" (state registration number 0116U004031).

\section{ORCID and contibutionship:}

Nadiya O. Fedchyshyn: 0000-0002-0909-4424 A,D,F

Olha V. Romanchuk: 0000-0001-8215-9741 E,F

Lesia I. Bilovus: 0000-0003-4882-4511 E,D

Oksana A. Mysyk: 0000-0002-8314-088X ${ }^{B, D}$

Nataliya M. Yablonska: 0000-0003-0818-2382 ${ }^{B, D}$

Viktor L. Nazaruk: 0000-0002-2833-3072 ${ }^{B, F}$

Tetiana I. Pantyuk: 0000-0003-0672-9663 ${ }^{C, E}$

\section{Conflict of interest:}

The Authors declare no conflict of interest.

\section{CORRESPONDING AUTHOR \\ Nadiya 0. Fedchyshyn}

Ternopil National Medical University

1 Maidan Volia st., 46002 Ternopil, Ukraine

tel: +30977008085

e-mail: fedushunno@tdmu.edu.ua

Received: 14.04 .2021

Accepted: 30.07 .2021

A - Work concept and design, B - Data collection and analysis, C - Responsibility for statistical analysis,

D-Writing the article, $\mathbf{E}$ - Critical review, $\mathbf{F}$ - Final approval of the article 